\title{
Map templates in a European Research program: emerging consensus, without compromising cartographic innovation
}

\author{
Christine Zanin, ${ }^{\mathrm{a}}$ Ronan Ysebaert, \\ ${ }^{a}$ University Paris Diderot - UMR Géographie-cités / UMS RIATE; christine.zanin@univ-paris-diderot.fr \\ ${ }^{b}$ University Paris Diderot - UMS RIATE; ronan.ysebaert@ums-riate.fr
}

\begin{abstract}
Maps are produced to represent geography and spatial organization of natural or human features. They deliver spatial forms where each graphic object have its influence and can change the perceived message. The cartographic realization participates to the geographical analyzes and helps their memorization. Adding innovation to this achievement ensures a perception and understanding of the scientific information delivered. The question is to understand what innovation is, when we speak about cartography. The underpinnings of the design and delivery of these representations are surely linked to developments in theory and technology applied to the geosciences, but not only. The purpose of this paper is to offer some ideas on the influence of an institutional framework on innovation and the relevance of a cartographic realization. Based on the example of the cartographic models construction in the framework of the research projects financed by the ESPON (European Observation Network for Territorial Development and Cohesion) Programme, we try to show how a framework that is too strict and fixed upstream of cartographic design can lead to a homogeneous and stereotyped production, without innovation or simply carto-graphic originality. In conclusion, we show how a close negotiation between funders and cartographers can help to evolve the cartographic scheme in place. Several proposals are put forward.
\end{abstract}

Keywords: Cartographic innovation, ESPON, European Institutions, Map harmonization, Map templates.

\section{Introduction}

Cartographic innovation is a fashionable subject. Nowadays, we cannot talk about mapping without talking about innovation. It seems that the technical and technological evolutions that have led to a popularization of the whole cartographic production chain make the term of innovation mandatory when we speak about cartography. But what is behind this term of innovation? Is it to implement new mapping tools? Data processing? Web or mobile viewer? New devices? More efficient, more complex, more accessible features? More dedicated to this or that topic? More suitable? To what? New graphic semiology? New designs? More adapted to user's needs?

In fact, we understand innovation as equally a matter of not restricting itself to a too tight framework of cartographic construction as of setting up new modes of representation. Innovation thinking is talking about how to make right choices and fostering sparks of creativity. The biggest part of an innovation process is the ability to avoid things in place and to let creativity express itself, even in the mapping process, from data collections to map creation, whatever the creation is about (technology, numeric development, devices applications, semiology, etc.).

The aim of this paper is to understand whether the construction of an imposed cartographic model, called here map template, does not interfere with the design of innovate and effective cartographic images, for decisionmaking support in the field of territorial planning within the framework of European institutions. This reflection is based on expertise and experience of several years within the ESPON Programme.

\section{ESPON, European applied research for spatial planning}

The European Observation Network for Territorial Development and Cohesion, called ESPON Programme, was adopted by the European Commission on 7 November 2007. Since then, three different programming periods have succeeded one another: ESPON 2006 (20072013), ESPON 2013 (2013-2016) and ESPON 2020 (2016-2020).

The aim of the 2006 program was to delivery applied research and studies on territorial development and spatial planning seen from a European perspective in support of policy development.

Some changes were brought to the ESPON Programme in 2013, specifying that the ESPON mission was to "Support policy development in relation to the aim of territorial cohesion and a harmonious development of the European territory by (1) providing comparable information, evidence, analyses and scenarios on territorial dynamics and (2) revealing territorial capital and potentials for development of regions and larger territories contributing to European competitiveness, territorial cooperation and a sustainable and balanced development". The actions carried through under the programme included different, however strongly interrelated operations such as applied re-search on different themes of European territorial dynamics, targeted analyses together with stakeholders which was is an important project type that makes use of ESPON 
results in practice, development of scientific Platform supported by an ESPON Database project and actions dealing with territorial indicators and monitoring as well as tools related to territorial analyses, typologies, modelling and updates of statistics.

The revised version of the ESPON 2020 Cooperation Programme was adopted on the 26 May 2016 by the European Commission. The ESPON 2020 Programme aims at promoting and fostering a European territorial dimension in development and cooperation by providing evidence, knowledge transfer and policy learning to public authorities and other policy actors at all levels. Its mission remains. The main objectives were still further refined: "to support the reinforcement of the effectiveness of EU Cohesion Policy and other sectoral policies and programmes under European Structural Investment (ESI) funds as well as national and regional territorial development policies, through the production, dissemination and promotion of territorial evidence covering the entire territory of the 28 EU Members States, as well as 4 Partner States of Iceland, Liechtenstein, Norway and Switzerland".

In order to achieve these objectives, The ESPON Programme manage a budget of $48,678,851.00 €$ with an EU contribution of $41,377,019.00 €$. In addition, the ESPON 2020 Programme receives a support of $1,850,000.00 €$ from the 4 Partner States (Iceland, Liechtenstein, Norway and Switzerland). The Managing Authority is based in Luxembourg and represented by the Ministry of Sustainable Development and Infrastructure Department of Spatial Planning and Development (DATER), Division for European Affairs.

\subsection{ESPON, an intensive map production programme}

ESPON Programme launched studies in various thematic fields (demography, land use, transport, socio-economic inequalities, etc.) to increase knowledge and effectiveness of the European Union Cohesion Policy under European Structural Investment funds. In this context, the need is high to provide "comparable, systematic and re-liable territorial evidence" for the ESPON area. One of the consequences is not only an intensive map production at this research program scale but also an intensive online map tools production from navigating and downloading da-ta to visualize cartographic results. Since the beginning of the ESPON Programme, the different projects have produced over 2,000 illustrations: $85 \%$ are maps, $10 \%$ are various graphic elements (pie charts, bar charts), and $5 \%$ are tables or schemas.

In 2013, we have realized for the ESPON managing authority, an analysis of all the graphic documents produced between 2007 and $2013^{1}$ within the program. Our considerations were based on a 981 maps corpus and lead to a general classification for the ESPON cartographic production. We have applied two

\footnotetext{
1 ECL ESPON 2013 Projects, Espon Cartographic Language http://www.ums-riate.fr/Webriate/wpcontent/uploads/2014/04/ECLReport_May2013_Task123_ok.pd
} $\mathrm{f}$ complementary multivariate statistical analysis methods to the set of the ESPON maps, described by 17 simple characteristics $^{2}$. Each characteristic is converted into a Boolean variable corresponding to the answers Yes=1 and $\mathrm{No}=0$ for each of the characteristics. The difference between two maps in this type of table can be measured by Chi-square metrics, and a hierarchical clustering procedure (Ward Criteria) provides optimal visualization of similarities and differences between the maps in the sample. The examination of the classification tree demonstrates that we can clearly distinguish two main clusters of maps:

- Type A: ESPON Core political maps. They represent $41 \%$ of our sample, and they are characterized by a set of common characteristics that defines a very homogeneous group: areal representation of regional indicators (the core maps focus on the presentation of indicators that are independent from the size of units. The cartographic magnitude of regional units is proportional to their area); Maps vertically oriented, covering only ESPON3.1 but not neighboring or candidate countries (the core maps exclude information that is not of direct interest for EU policy, and adopt the cartographic template used by DG Regio or Eurostat). Simple maps with simple message: only one indicator is presented on each map and no comparison is possible.

- Type B: ESPON strategic exploratory maps. They can be defined negatively as those that do not belong to the previous group of ESPON core maps. This group is indeed very heterogeneous and corresponds to a different research strategy, which has been developed by ESPON in order to meet long-term political objectives of territorial cohesion, rather than short-term demands for information related to structural funds. We can basically distinguish four different types of maps, corresponding to different paths of development in the ESPON program.

We have also pointed out some particular cartographic issues concerning the effectiveness and the complexity of ESPON Cartographic which established weaknesses and strengths of ESPON Cartographic production (Table 1). The main weaknesses of the maps produced are based on 3 main topics: a too little originality of the maps, with a lot of elementary productions and too much standardization; marked typological homogeneity among maps, and a very little innovative production. So, one of the main problem seems to be related to a homogeneity problem. In fact, the managing authority of the ESPON programme seeks to put forward a strong visual identity which also involves the will to homogenize, not necessarily the cartographic production, but certainly

\footnotetext{
${ }^{2}$ These characteristics describe every map by a set of 7 main items: Number of maps, Combination of maps, orientation, and spatial units considered, spatial coverage, cartographic representation types, and indicators represented.
} 
their visual aspect so that one recognizes from the outset an ESPON map. This objective can be achieved in particular by requiring projects to carry out their maps within the framework of a pre-established graphic model. Specific templates have to be used in order to display thematic phenomenon on maps, including layers of reference at European level or advices to dis-play socioeconomic phenomenon on maps and requirements regarding the harmonized layout to follow. In ESPON language it's what we call a "MapKit".

\begin{tabular}{|c|c|c|}
\hline Evidences & Weaknesses & Strenghts \\
\hline $\begin{array}{l}80 \% \text { of the ESPON } \\
\text { maps are designed on } \\
\text { NUTS nomenclature } \\
87 \% \text { of figures can } \\
\text { comprise a single } \\
\text { illustration } \\
79 \% \text { of ESPON maps } \\
\text { use a unique semiotic } \\
\text { representation } \\
68 \% \text { are choropleth } \\
\text { maps are } \\
81 \% \text { of maps are } \\
\text { images constructed on } \\
\text { European scale } \\
\text { among which } 55 \% \\
\text { use the restricted } \\
\text { scale of the ESPON } \\
\text { Space }\end{array}$ & $\begin{array}{l}\text { Without the text, } \\
\text { many of the maps } \\
\text { would not be easy to } \\
\text { understand; } \\
\text { Little originality, with } \\
\text { a lot of elementary } \\
\text { productions and too } \\
\text { much standardization } \\
\text { (blue lines, base maps, } \\
\text { colors, title, legend, } \\
\text { orientation, } \\
\text { sources....); } \\
\text { Marked typological } \\
\text { homogeneity among } \\
\text { maps; } \\
\text { No marked interest in } \\
\text { the aesthetic qualities } \\
\text { of a map; } \\
\text { Reflection } \\
\text { cartographic issues is } \\
\text { often lacking; } \\
\text { Little innovative } \\
\text { production; } \\
\text { Layout is never } \\
\text { designed in relation } \\
\text { with the map message. }\end{array}$ & $\begin{array}{l}\text { Strong visual } \\
\text { identity; } \\
\text { No major } \\
\text { mistakes in the } \\
\text { use of graphic } \\
\text { semiology; } \\
\text { Transfer of the } \\
\text { data to the map } \\
\text { generally well } \\
\text { managed; } \\
\text { Data correctly } \\
\text { identified. }\end{array}$ \\
\hline
\end{tabular}

Table 1. ESPON Cartographic production: Evidences, weaknesses and strengths (Source: ECL 2013,39)

Based on our MapKit creation experience, we try to show in this communication how too homogeneous instructions block cartographic innovation and we highlight several key elements that prevail in cartographic production and in-novation within a transnational research program scale in Europe and which are based on a clever mix of organizational, diplomatic, operational and mapping issues.

\section{ESPON MapKits 2007 - more harmonization leads toward too much homogenization}

All the maps designed within ESPON Programme are realized by a lot of contributors: academics, private companies having a large variety of habits in term of map production. It is consequently important for the coordinators of ESPON that all contributors involved in the program start with a common material to produce these maps.

This section analyzes four topics that influence the creation of a ESPON MapKit: the ESPON map template (3.1), characterized by a strong visual chart. Secondly, the instructions resulting from political consensus to display European disputed areas and boundaries on maps (3.2). Thirdly, the need to use geographical layers of reference commonly used to display European territories on maps (3.3). Finally, advices are given to ESPON projects regard-ing the choice of specific semiology to be used (3.4).

\subsection{The ESPON Map template}

A MapKit can be considered as a concatenation of geographical layers (regions, boundaries, capital cities, etc.), displayed in a adapted layout which provides the ESPON Map identity and implemented for several GIS softwares (QGIS and ArcGIS) and other tools useful to produce thematic maps (Computer-Assisted Drawing software). The template displayed below in figure 1 was the reference for the ESPON Programme 2007-2013 and used until 2016.

The figure 1 presents several key elements which lead the map production within ESPON to ensure a convenient harmonization and "corporate identity" and may be discussed:

- $\quad$ Each map produced must systematically include the layout (blue stripes), sources correctly filed, logos and European Commission publicity. These blue stripes occupied $5 \%$ of the map template area, which can be considered very important. It must also include a disclaimer dedicated to protect the funders of the pro-gram regarding the message delivered by the map.

- ESPON maps must be built using specific detailed geometries for displaying European territories. The boundaries and coast line used in the previous ESPON Programme were characterized by a very high accuracy. It is certainly suitable for topographic maps, but the same is not true for thematic maps which are our subject here. A map drawn with over-precise contours, far from adding accuracy, adds "noise" to the interpretation of a map that is counterproductive.

- Remote territories (French Guyana, Martinique, Guadeloupe, Canarias, etc.) must always be displayed in specific boxes in the right side of the map.

- The textual information (title, legend) is located out of the layout of the map.

- Specific and fixed styles are defined for capital cities, territories out of the study area, boundaries color and with, sea color (dark blue), and data sources. 


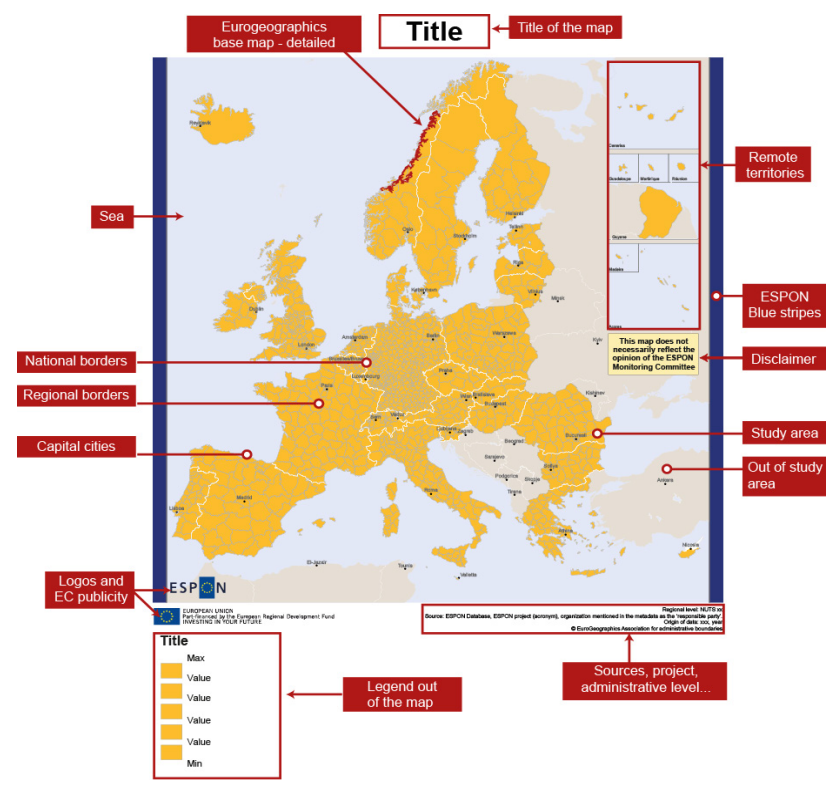

Fig. 1. ESPON 2013 Map Template (Source: ESPON Programme 2007-2013)

\subsection{Guideline for a consensual representation of European countries}

ESPON is partly financed by European Member States, and for diplomatic and cultural reasons, the ESPON Programme provides instructions resulting from a political consensus to display European specificities (and conflicts) on maps: for example, displaying Northern Cyprus on maps, choosing the boundary line width between Kosovo and Serbian Republic. Figure 2 shows the guidelines provided to projects involved in the ESPON Programme for the map representation of Cyprus, located in the South-Eastern part of the ESPON Map Template and for disputed borders located in the study area.

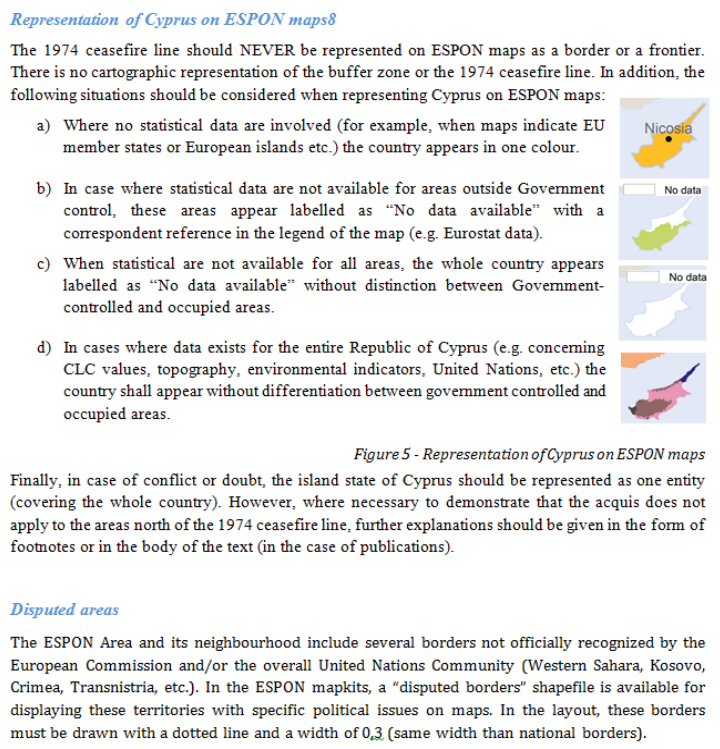

Fig. 2. Representation of Cyprus and disputed areas in ESPON Maps (Source: ESPON, Using ESPON MapKits, 2017)

\subsection{A limited number of geographical layers, protected by copyright issues}

The layers used in the previous ESPON Programme were provided by Eurogeographics, representing the European National Mapping, Cadastral and Land Registry Authorities (60 organizations from 46 countries). One important issue regarding the use of this accurate data source is the price: for an unlimited user band and a full European coverage for local territorial units, the annual license price is 51,500 euros $^{3}$. It's a major limitation for the dissemination and the reproducibility of ESPON analysis: project can disseminate the datasets, but not the geometries they used to display their results on maps.

\subsection{The use of colors}

In visual communication, the use of color is complex, and its cartography it is a very delicate matter. Color possesses intrinsic properties, each color corresponding to a specific wavelength. But color also has psychological and cultural connotations that may be very strong and pervasive. One color could intrinsically mean different things. Two or three generations of schoolchildren remember the cartographic colors of the Cold War: red for the baddies and blue for the goodies (Rekacewicz, 2006). For example, blue is the color of calm and serenity, it is consensual; it is the color of Europeans and the Western world, whatever the social or professional environment. Blue is not a striking color. On the contrary, red is "fire, blood, love and hell" (Itten, 1961), it is a proud color of ambition, it is insolent, violence, crime and sin are associated with it. Choosing colors is all about the message you want to deliver. It's not a trivial issue. This is particularly true for maps developed in a supranational context, as is the case in the ESPON Programme: in the mapping guide dedicated to ESPON projects (2011). In this paper, it is reminded that "the choice of color is very subjective and cultural. However, it is quite confusing if two different ESPON maps are published where red has a positive meaning in one of the maps and a negative meaning in the other map. It is therefore suggested, "When combining red (warm colors) and blue or green (cold colors), red is "not good/negative" and blue is 'good'/'positive"'. In ESPON, the choice of colors meaning is indeed the result of a pragmatic compromise between different cultural traditions to lead to homogeneous interpretation of color meaning.

However, this rationalization process omits the fact that green does not have the same meaning in France (nature conservation), in North Africa (Islam) and in Ireland (national color). The use of this color in the European setting will therefore be perceived differently according to the nationality, cultural origin or religion of the reader.

\subsection{Conclusions}

These ESPON guidelines reveal that the visual identity of ESPON Maps is strong. In terms of maps, it was one of the objectives of the program regarding communication

\footnotetext{
http://www.eurogeographics.org/products-and-services/licenseour-products
} 
issues: any reader of maps produced within ESPON is struck by this layout templated by these characteristics blue stripes. The result is also very strong on quality and variety of map productions: geographical objects, representation modes and designs are highly affected.

The ECL project underlined also that there is considerable similarity between ESPON cartographic production and that of other European organizations. Cartographic originality is observed when institutions are not weighed down by excessive standardization, which seems to be damaging for creativity and innovation. Innovation also occurs when the maps are designed for territories that do not involve the usual spaces represented, for instance when a given state produces a map of Europe. Innovation also appears to be favored by the closeness of links between the institution producing the map and scientific, Geomatics or Geovisualization research.

\section{Proposals for more cartographic innovation in the ESPON 2020 Programme}

Using this operational background, we aim at questioning the MapKits production process occurring before the map representations: How rethinking the MapKits for reducing potential negative impacts? What role can they be assigned to reduce their impact on excessive homogenization and the transmission of an impoverished cartographic message? Which message could be conveyed by a map created in the framework of these European institutions? Accumulated experience shows that, within a strong institutional context (as the ESPON one), it requires generally to negotiate very often with the authority managing these programmes to challenge too restrictive imposed guidelines for proposing innovation (layers to use, colors to choose, etc.). It requires time, but it is not impossible...

To illustrate this idea, we deliver in this section the inputs of the ESPON 2020 MapKits project, coordinated by UMS RIATE. It aims at implementing some of these considerations within the new programming period of ESPON (2016-2020). Taking into account the remaining constraints of such European research program (visual identity, providing a set of geographical layers of reference to people involved in this framework, how to display disputed borders on maps), this project has provided a revised version of ESPON MapKits. Main innovations are detailed in this section. It consists mainly in improving the design of the ESPON layout (4.1), and providing a set of multiscalar open source geographical layers, adapted to thematic cartography purpose (4.2).

\subsection{Input 1 - Improvement of the design of the ESPON layout}

The cartographic layout to be followed by people involved in the ESPON 2020 Programme, shown in figure 3 , will differ significantly as compared to the one used in the previous programming period (fig.1). Efforts have been made in two major directions: (1) Improving the overall graphical quality of the layout by focusing on the thematic message to be conveyed by the map. (2)
Letting the choice to the ESPON map creators to display on the map some elements or not.

Regarding the design, the new layout use generalized geographical layers adapted for thematic purpose which has an immediate effect on the congestion of the coastline on the cartographic rendering; the eye is less attracted by an overload of ink. Textual information (titles, legends) are more hierarchized and are better incorporated within the map layout. Less area is dedicated to the "ESPON vertical blue stripes" ( $3 \%$ of the map template, $5 \%$ by the past). Finally, Micro-States (Liechtenstein, or Malta) and remote areas (French, Portuguese and Spanish islands) are displayed with a less important degree of map generalization. The sea is also less dark as compared to the past, Thus attracting less attention.

The ESPON map template is also more flexible. Depending of the creation context and the message to be conveyed by the map, the map creator can choose to display or not the name of the European capitals and/or capitals of the European neighborhood. The same is also true for regional borders. Finally, it is possible to display the map legend at several different places of the map template.

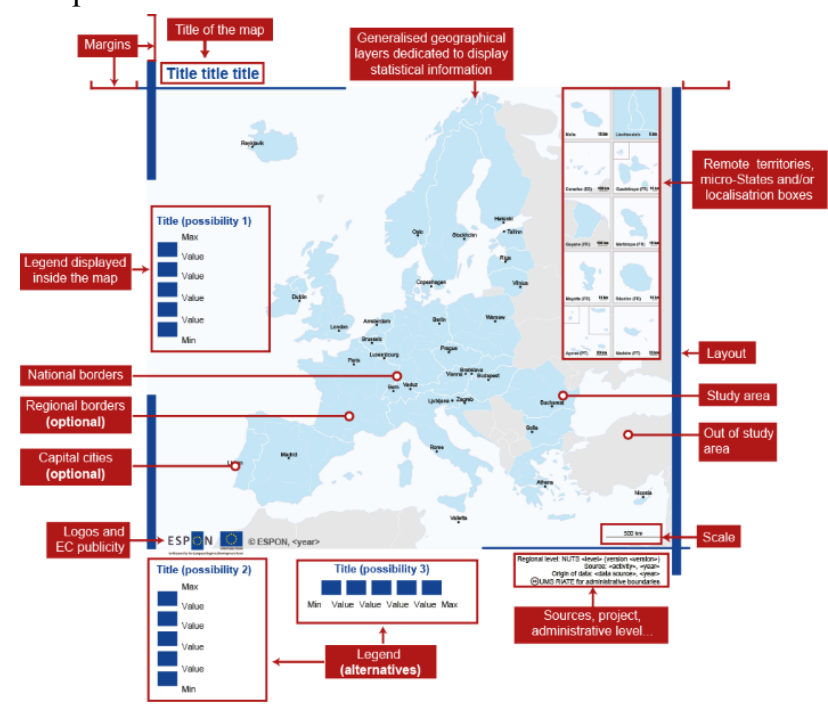

Fig. 3. New map template for the ESPON 2020 Program (Source: ESPON 2020, MapKits project, 2017)

\subsection{Input 2 - A coherent set of open source geographical layers}

In the ESPON context, geographical layers are used for two purposes: mapping and analysis. Criteria of quality and suitability (i.e. 'fit for purpose') of individual geographical layers may be different depending on considered uses: for analyses, the key criterion is precision. It is important to consider whether files that are combined in an 'analytical MapKit' are consistent, so that analyses based on their overlay produce reliable results; for mapping, the key criterion is informational value. The objective is to facilitate the transmission of a clear cartographic message to the recipients of each map in an efficient way. This implies that, what is called here 'cartographical noise' (e.g. in this example, unnecessarily detailed boundaries) must be eliminated. 
A structured and coherent set of geographical layers for thematic mapping and analytical use were proposed to the ESPON community (table 2). Depending on the purpose of the cartographic need, the ESPON Mapkits are based on four different sets of geographical layers:

1)G.R.E.A.T. World: a world-wide layer of countries and territories with a high degree of generalization,

2)G.R.E.A.T. Europe: pan-European layers of regions, countries and territories, which provides suited and seamless layers for thematic mapping from NUTS3 to NUTS0 levels.

3)Voronoï: pan-European (32 countries at LAU2 level) layers for local and regional territorial units,

4)The ESPON LAU2 Census 2011 Map: pan-European (32 countries) collection of layers representing Local Administrative Units (LAU), regional and national units compiled and based on inputs from National Map-ping and Cadastral Agencies (NMCAs), with a resolution corresponding to a scale of 1:100 000 .

The G.R.E.A.T. and Voronoï layers are available under Creative Commons License BY-SA and are suitable for thematic cartographic purpose. The use of ESPON LAU2 Census 2011 layer is the only one strictly reserved to teams involved in the ESPON Programme and cannot be disseminated. This layer is adapted to GIS processing.

This "multilevel layers supply" approach will benefit to ESPON map creators for having wider possibilities for displaying territorial phenomenon on maps: more territorial units of reference and more study areas are now avail-able. Consequently, the ESPON 2020 MapKits project has focused its activities to produce 25 MapKits covering emerging needs of cartography in a European perspective. Firstly, by proposing a large set of geographical objects (NUTS, LAU, grids, neighboring countries). Secondly, by developing, these layers, for several geographical contexts in a multiscalar perspective (Zooms, transnational cooperation areas, Europe, World). ESPON map creators are also invited to create their "own" MapKit if needed (for case-studies). Specific guidelines have been written in that sense. Nevertheless, the main issue remains the use of the creative commons license for these geographical layers. Thanks to this major change, it will be possible to better disseminate and reproduce ESPON material and results, for example, to students or academics not directly involved in the ESPON Programme.

\section{Conclusions: Suggestions for more innovative maps}

The purpose of this paper was to understand how an institutional framework too strict and fixed upstream of cartographic design could hold back on cartographic realization innovation. So as to overcome these obstacles a close negotiation between funders and cartographers must be done.

Several but simple proposals are put forward in order to open negotiations on concrete and operational solutions for always allow more variety on map creation:
- More templates, from the local to the global scale;

- More geographical objects (cities, boundaries for discontinuities calculation, grids, local units);

- As much as possible use Creative Commons License to disseminate and further improve them;

- Easier guidance to build a more personal MapKit instead of imposing a too closed upstream model;

- Do not hesitate to use a more generalized base map to improve a lot the efficiency of the stated message of a thematic map;

Moreover, we wish to point out that, beside all the elements to be considered and involved in a map template creation, map innovation is also dealing with more thinking when it comes to choose a mode of representation: one can not hesitate to use different tools for more innovative cartography like web-based, dynamic, more original representation such as cartograms, smoothing maps, etc. In order to facilitate the dissemination of these innovative techniques within a wider community, new tools are continuously developed and can be properly used for designing such maps, out of classical GIS and to reinforce the aesthetical aspects of maps: we can point out tools like Magrit ${ }^{4}$, Scapetoad $^{5}$, etc).

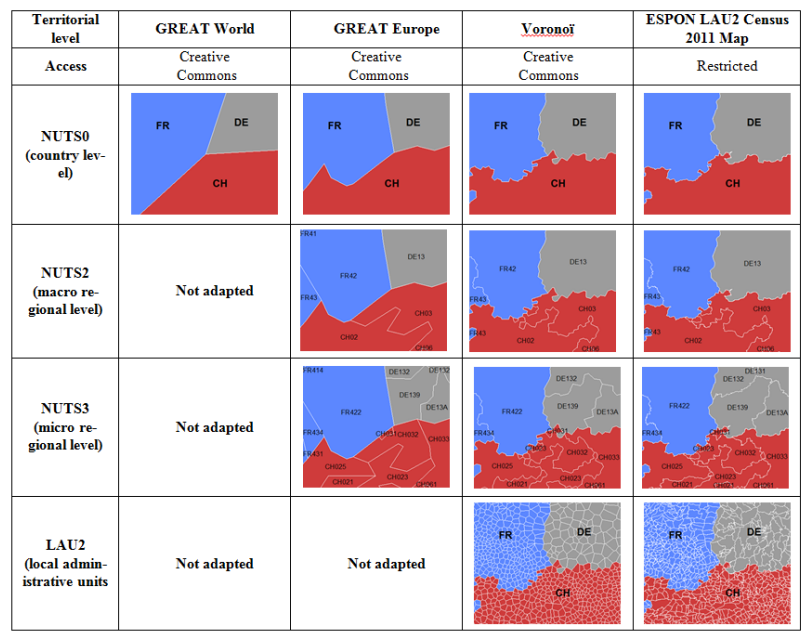

Tab. 2. Several geographical layers adapted to cartographic purpose. French-German-Swiss Example.

\section{References}

Béguin, M., Pumain, D. (2014). La représentation des données géographiques - statistique et cartographie, Armand Colin.

ESPON ATLAS. (2013). Territorial Dimensions of the Europe 2020 Strategy.

\footnotetext{
${ }^{4}$ http://magrit.cnrs.fr/ : online thematic cartographer developed in 2017 by UMS RIATE (France)

${ }^{5} \mathrm{http}: / /$ scapetoad.choros.ch/ : ScapeToad uses the Gastner/Newman diffusion-based algorithm to adapt map surfaces to user-defined variables developed by University of Tours, Polytechnics of Lausanne and Chôros Laboratory.
} 
https://www.espon.eu/export/sites/default/Documents/Pu blications/ATLAS2020/194650_ESPON_ATLAS_-

Final_version.pdf

ESPON Atlas. (2014). Mapping European Territorial Structures and Dynamics. http://atlas.espon.eu/

Itten J. (1961). The Art of Color, New York, John Wiley \& Sons, Inc

Rekacewicz, P. (2006). La cartographie entre science, art et manipulation. Atlas du monde diplomatique.

Zanin, C., Lambert, N., Ysebaert, R. (2011). Mapping guide, cartography in ESPON 2013, ESPON 2013 Database Project, and Tech-nical Report. ESPON report,

https:/www.espon.eu/export/sites/default/Documents/Pr ojects/ScientificPlatform/ESPONDatabaseII/TR_Mappi ngGuideESPONProjects.pdf accessed in February 2017

Zanin, C., Lambert, N., Davoine, P.-A., Mathian,H., Saint-Marc, C. (2013). ESPON Cartographic Language, Interim Report, review report, ESPON Cartographic Language project.

Zanin, C., Lambert, N. (2013). Proposal for a modernised ESPON Cartographic Language, ESPON Cartographic Language project.

Lambert N., Zanin C. (2016). Manuel de cartographie. Principes, méthodes et applications. A. Colin 